
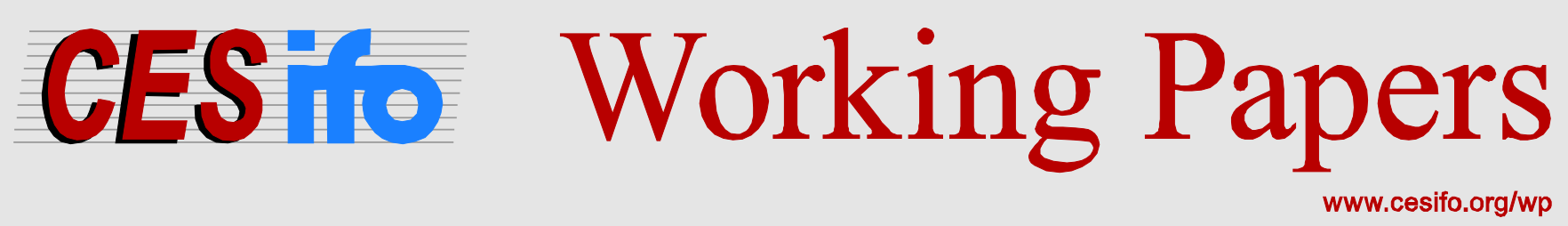

\title{
Pricing the Transfer of Intellectual Property as a Problem of Second-Best Tax Policy
}

\author{
Wolfram F. Richter \\ Markus Breuer
}
CESIFO WORKING PAPER NO. 5340
CATEGORY 1: PUBLIC FINANCE
MAY 2015

An electronic version of the paper may be downloaded

- from the SSRN website:

- from the RePEc website:

- from the CESifo website:

wWw.SSRN.com

Www.RePEc.org

www.CESifo-group.org/wp 


\title{
Pricing the Transfer of Intellectual Property as a Problem of Second-Best Tax Policy
}

\begin{abstract}
The adequate pricing of intellectual property ("IP”) for tax reporting is a largely unsettled issue. Transactional profit-based methods are on the rise although only rated as "methods of last resort" by the OECD. This paper focuses on regulated profit splitting and compares this transfer pricing rule with one allowing multinationals to price IP freely subject to the constraint that the price used for tax reporting is also used internally. The standard of comparison is global efficiency in R\&D. The model is one of second best. It allows for internationally differentiated tax rates and non-deductible effort costs in the production of know-how.
\end{abstract}

JEL-Code: H250, O340, M480, F230.

Keywords: transfer pricing rule, intellectual property, profit split method, allocational efficiency, second-best policy.

\author{
Wolfram F. Richter \\ TU Dortmund University \\ Department of Economics \\ Germany-44221 Dortmund \\ Wolfram.Richter@tu-dortmund.de
}

\author{
Markus Breuer \\ SRH Hochschule Heidelberg \\ Department of Business Administration \\ and Economics \\ Ludwig-Guttmann-Str. 6 \\ Germany-69123 Heidelberg \\ Markus.Breuer@Hochschule- \\ Heidelberg.de
}

March 2015

Valuable comments and suggestions made by Stefan Homburg, Sören Bo Nielsen, and Ulrich Schreiber are gratefully acknowledged. 


\section{Introduction}

Intellectual property (“IP”) is of increasing importance for multinational enterprises ("MNEs"). In the last three decades IP and intangibles have become their dominant assets. The value of patents, trademarks, copyrights, and other intangible assets as a percentage of the largest US companies' market value is estimated to have increased from $16.8 \%$ in 1975 to almost 80\% in 2005 (Parr, 2013, citing Ocean Tomo). As a result, the adequate pricing of IP in transactions between the affiliates of multinationals has become a pressing issue for corporate management and even more for tax authorities. The standard methods for the determination of arm's length transfer prices - the comparable uncontrolled-price method, the cost-plus method, and the resale-minus method - often fail to be applicable for intangibles ${ }^{1}$. Therefore, transactional profit-based methods are accepted by an increasing number of countries instead (OECD, 2008). This development is remarkable, as those methods had previously been described as last resort methods in the OECD Transfer Pricing Guidelines.

This paper is motivated by the wish to understand the virtues of a profit-based transfer-pricing rule. The aim is to show that the rating of profit-based methods as last resort solutions is inappropriate. Such methods do have their distinct merit in the pricing of transferred IP.

The framework chosen for showing this is one in which the management of a MNE can be centralized or decentralized and in which the allocation of R\&D activities suffers from two tax distortions. One results from internationally differentiated tax rates and the other results from incomprehensiveness in the tax deductibility of costs. In such a framework, it is shown in this paper that the profit-based transfer-pricing policy has appealing properties. It does not distort the choice between centralized and decentralized management. And it constitutes a reasonable policy compromise between the requirements of first-best and second-best efficiency and also between the opposing interests of high- and low-tax countries.

Various simplifying assumptions help to make the theoretical analysis tractable. The first one constrains the set of profit-based methods to be studied. The sole focus will be on the profitsplit method. According to this method, profits resulting from a transaction are shared between the legal entities involved in a fixed proportion. Popular examples are the Goldscheider rule requiring the licensee to pay $25 \%$ of its expected profits for the product that

\footnotetext{
1 Already in the early 1970s the Canadian minister of finance stated that it "is generally impossible for the revenue authorities [...] to determine the reasonable amount that should be charged for technical or managerial know-how by a parent company to its subsidiaries except, perhaps in the very rare instance where there is a comparable arm’s length transaction to use as a yardstick.” Quotation taken from Benson (1971).
} 
incorporates the intellectual property at issue to the grantor of the license (Goldscheider, Jarosz, and Mulhern, 2005) ${ }^{2}$ and the Knoppe formula allocating 25\% - 33\% of the expected profit to the licenser (Knoppe, 1972). For other sharing rules based on hypothetical negotiations between independent parties see Boos (2003, p. 204).

In practice, particular splitting parameters are proposed by the MNE. It is then up to the tax authorities to accept the proposed parameters. One may rightly assume that extreme proposals by the former are hardly accepted by the latter. In fact, the ultimate choice can be a contentious issue between firms and tax authorities.

The present paper deviates from this practice by assuming that there is no leeway in choosing the splitting parameter. The idea is that there is a unique parameter set by law and exogenous to the MNE under consideration. One may think of a kind of internationally harmonized policy requiring profits to be split in fixed proportion. In what follows, such a policy regime is meant whenever we speak of regulated profit splitting. Under this regime, the profit that the affiliate of a MNE earns by exploiting provided IP is shared in a fixed proportion with the supplying affiliate. By assumption, the licensee has not contributed to the development of the know-how for which the license is paid. Hence, the splitting parameter cannot be justified by the individual contributions of the licensee and the licenser. The parameter is totally exogenous for the related parties. ${ }^{3}$

This paper's objective is to understand the merit of regulated profit splitting from a policy perspective. The paper does not aim at characterizing any particular splitting parameter as being the optimal one. It is however shown that any fixed choice larger than zero and smaller than one hundred percent has certain advantages over a competing pricing rule which a priori seems to be more appealing and which we call uniform pricing.

By definition, uniform pricing allows multinationals to price IP freely, subject to the constraint that the price used for tax reporting is also used internally. Such a transfer pricing rule has recently been proposed by Desai and Dharmapala (2011). They call it the performance-related principle and recommend it as an alternative to the arm's length principle. We rather prefer to speak of uniform pricing as we find this term to be more

\footnotetext{
${ }^{2}$ It has to be noted that the Goldscheider rule has not been undisputed in transfer-pricing practice and that it has even been rejected by the US Federal Circuit in 2011 ('Uniloc vs. Microsoft').

3 There is a strand of literature assuming that the splitting parameter can be derived from individual contributions: "(The profit split) method aims to split the total profit earned on a transaction by all group companies involved in it using an 'equitable' formula, eg by reference to capital employed" (Miller et al., 2009, Sec. 14.19, p. 318). See also pertinent contributions in Schön and Konrad. (2012).
} 
informative. Desai et al. argue that the uniform pricing requirement would limit the scope for firms to opportunistically reallocate taxable income across jurisdictions. Furthermore, they point out that the rule sustains global production efficiency in a simple model.

Replication of the efficiency result in this paper reveals that it relies on two critical assumptions (Proposition 4). One is that all costs of know-how are tax deductible. The other is that the management of the MNE is decentralized. Decisions concerning the development and use of know-how are delegated to divisions organized as independent profit centers. The sole function of transfer pricing must be the balancing of the divisions' demand and supply of know-how on a perfectly competitive internal market. This assumption is clearly unrealistic when the choice of particular transfer prices affects the MNE's tax bill. If there is an international gap in corporate income tax rates, MNEs can use transfer pricing for tax-saving profit shifting. Uniform pricing reduces the scope but fails to eliminate it completely.

If firms react to taxation, uniform pricing cannot sustain first-best (production) efficiency (Propositions 5 and 6). However, inefficiency results as well if the profit generated from using know-how in a division other than the developing one is split and shared between the two divisions for tax purposes (Proposition 2). The sharing has the effect that the developing division's internal and external returns to $\mathrm{R} \& \mathrm{D}$ are taxed differently. Hence, allocational efficiency is clearly hampered by both transfer pricing rules. Less clear is which one should be preferred from a policy perspective.

This paper argues that both rules do have their distinct merits. The advantage of uniform pricing is that it allows profit shifting not only in cases in which it is inefficient. In fact, profit shifting may have efficiency enhancing effects. This is so when costs of know-how are not deductible. It is then possible to show that uniform pricing dominates all specifications of regulated profit splitting including residence and source taxation. In other words, uniform pricing dominates the competing pricing rules in some second-best sense. The downside of uniform pricing is that it sets incentives for centralized management and that it is not unambiguously dominating in the first-best sense. Another reason to prefer regulated profit splitting is that this rule offers scope for policy compromises. By appropriately setting the splitting parameter one is able to compromise between the requirements of first-best and second-best efficiency and also between the opposing interests of high- and low-tax countries.

The paper is structured as follows: Section 2 surveys the related literature. As we shall see, it is largely an open question how to regulate the pricing of transferred know-how efficiently. 
Section 3 sets up the model of a multinational enterprise. It is argued that incomprehensiveness in the tax deductibility of costs is an issue in R\&D. Section 4 studies regulated profit splitting. Section 5 looks at the uniform pricing rule. Section 6 compares the two rules and section 7 summarizes and concludes.

\section{Related literature}

As one of the first economists to do so, Hirshleifer (1956) used a model-based approach to discuss the pricing of transfers between related entities. However, business models have changed since the fifties, and the special characteristics of today's value chains - the relevance of IP, globalization of business, etc. - and international tax differentials were not considered in early works.

Current research in the field of transfer prices often has an empirical focus. For instance, royalty payments, $R \& D$, advertising activities, and the holding of patents and intangibles are found to be particularly tax-sensitive. See e.g. Grubert (2003); Mutti and Grubert (2009); Dischinger and Riedel (2011); Karkinsky and Riedel (2012); Griffith, Miller, and O`Connell (2011); Heckemeyer and Overesch (2013); Dharmapala (2014). The effect of taxation on profit-shifting activity is to be documented by this kind of research. The normative question of policy design is not in the focus.

Policy design calls for theoretical analysis. Probably the first model dealing with the question of R\&D expenditures is Horst (1973). Although his model considers expenditures that make the MNE's goods more valuable the analysis can easily be applied to cost-reducing investments, managerial know-how, etc. The shadow price given by the equalization of marginal revenue and marginal cost of investment offers an appropriate basis for charging the subsidiary its share in the R\&D program. This pricing policy ensures efficiency within the MNE.

Theoretical papers analyzing transfer-pricing policy from a global efficiency perspective are rare. One of the first studies - if not the first one - is by Edlin and Reichelstein (1995). By using a model of negotiated transfer pricing these authors showed that an efficient outcome requires fixed-price contracts prior to making investment decisions. The parties are assumed to agree on an efficient transfer and an associated payment that splits the generated surplus. Thus, specific investments made by the individual subsidiaries are effectively protected under imperfect information. 
A notable result of Wellisch (2003) is to show that the parameter of profit splitting must be exogenously fixed if the effect of splitting on decisions made by the MNE's management is to be neutralized.

A paper which is related to the present one in spirit is the one by Desai et al. (2011). These authors plead for replacing the arm's length principle with what they call the performance related principle. As mentioned already, the implementation of this norm amounts to what is called the uniform-pricing rule in the present paper.

The potential merits of decoupling, i.e., the non-uniform use of transfer prices for internal and external statements, is investigated in a number of papers. An example is Johnson (2006), who sets up a sequential model in which two related legal entities (profit centers) trade IP. One firm invests in R\&D leading to a certain output of IP which can be sold to the other firm in a second step. Johnson shows that decoupling can boost the overall group profit. Johnson's sequential setting is picked up by Hiemann and Reichelstein (2012). These authors confirm the merits of decoupling. It allows MNEs to make better investments and also to earn higher after-tax profits.

A broader view on transfer-pricing rules and regimes is provided by Nielsen (2014). He presents a model which is designed to illustrate the possible tensions between the managerial purposes of transfer pricing and the workings of competing transfer-pricing rules. The focus is on a MNE delegating its quantity-setting power to a subsidiary which is engaged in CournotNash competition with an uncontrolled second supplier. Among the four policy regimes studied are those of uniform and non-uniform pricing. Intellectual property and the pricing of its transfer are however not considered in this study.

The policy question of how to respond to profit shifting and 'aggressive' tax planning by MNEs is raised by Fuest et al. (2013), though without relying on formal modeling. The authors deduce a split recommendation. In the short run, they plead for extending withholding taxes in an internationally coordinated way. For the longer perspective, they recommend a more fundamental reform like formula apportionment or a move towards destination-based taxation. Such proposals find little support by the subsequent analysis if taken literally. If they are however interpreted as a general plead for strengthened source taxation, support is provided. 


\section{The model of a multinational enterprise}

Consider a multinational enterprise with two divisions producing output $F=F(I, K)$ and $f=f(I, k)$ for third-party customers at a price normalized to one. The inputs are capital $K$ and know-how $I$. The letter $I$ is meant to suggest intellectual property. Capital stands for all those factors which can be contracted on perfect markets. The real rate of interest is denoted by $r$. By contrast, know-how cannot be contracted on markets. It is developed within the MNE at costs $V(I)$ which are convex and increasing, $V^{\prime \prime}, V^{\prime}>0$.

Know-how is modeled as a non-rival production input. This explains why $F$ and $f$ are both stated as functions of $I$. Let know-how be developed by the division the production function of which is denoted by $F$. We call this division the developing one. The other division is called the sharing division as it is assumed to share the developed know-how. Marginal productivities $F_{I}, F_{K}, f_{I}, f_{k}$ are positive and decreasing.

Corporate income is taxed at rate $t$ in the country of $f$ and at rate $T$ in the country of $F$. T may exceed $t$ but need not to do so. Still, $T>t$ is the more realistic case because R\&D activities are typically undertaken in advanced countries which tend to be among the high-tax countries. By assumption, capital costs are tax deductible. Hence, capital must be considered to be financed by debt at the margin. The simplifying assumption that capital costs are tax deductible holds throughout the analysis. As to the costs of developing know-how we, however, follow a more flexible modeling strategy. Those costs can be but need not be tax deductible. In fact, we shall study both scenarios with the intention to analyze the particular effect which the non-deductibility of costs of know-how has on corporate decisions. Nondeductibility is an issue for the following reason.

Know-how has to be developed by humans whom we call developers. Such individuals tend to be highly skilled employees who need to be incentivized and compensated for the effort caused by $R \& D$ activities. If the remuneration is chosen to be equity based, the nondeductibility of costs is a clear issue. For a recent discussion of the resulting problem of separating capital income from labor income see Griffith and Miller (2014). Another more model-based way of justifying the assumption of an incomprehensive tax deductibility of costs is as follows.

Assume that there is just one developer and that $W$ is the wage rate paid to him or her per unit of $I$. In such a setting the developing division bears wage costs, $W I$, while the developer bears 
costs of effort. Let $V(I)$ capture those costs of effort. Even if the remuneration paid to a developer is fully tax deductible at the corporate level, the effort cost is not so at the private level. The base on which the developer is taxed is wage income and not rent income. In order to demonstrate, that non-deductibility can be an issue at the corporate level we need to point out a mechanism by which the private costs of effort are transformed into corporate costs of know-how.

A plausible mechanism is based on the following two assumptions. One relates to taxation and the other relates to the determination of the developer's earnings. As to taxation, let us make the simplifying assumption that the same tax rate $T$ applies to corporate and private income. Such equality holds when the corporate income tax is fully integrated in the personal income tax. An example of a country having installed such a full imputation system is Malta. When the corporate income tax is fully integrated in the personal income tax, double taxation is no issue and the corporate cost of know-how equals the developer's income after tax. The final step is to argue that $(1-T) W I$ equals $V(I)$. Such equality is obtained when the MNE has control over $W$ and when the developer has to accept $W$ or to choose an outside option providing utility $u$. In this case, the firm's choice of $W$ has to respect the participation constraint $(1-T) W I-V(I)=u$. By way of normalization, $u$ can be assumed equating zero. The idea is that the developer receives compensation for the normalized disutility of effort, but not more. In the MNE's optimum, the participation constraint is binding and $(1-T) W I$ can be replaced with $V(I)$ as was to be demonstrated.

When know-how produced by the developing division is shared with another division, a royalty payment has to be specified. We allow for decoupling which means that the transfer price used internally differs from the price used externally for tax reporting. Let $R_{i}(I)$ be the royalty which the sharing division has to pay internally and let $R_{e}(I)$ be the royalty payment used for tax reporting. The sharing division's profit after tax results from subtracting the corporate tax from profit,

$$
\pi \equiv\left[f(I, k)-r k-R_{i}(I)\right]-t\left[f(I, k)-r k-R_{e}(I)\right] .
$$

The developing division's profit after tax is

$$
\Pi \equiv\left[F(I, K)+R_{i}(I)-r K\right]-T\left[F(I, K)+R_{e}(I)-r K\right]+(1-\delta T) V(I)
$$

where $\delta=1$ captures the case in which the cost of know-how is tax deductible while $\delta$ takes on the value zero if the cost is not tax deductible. 
This is the framework in which we study and compare rules by which the transfer of knowhow is priced. We start by analyzing regulated profit splitting as the profit-split method is increasingly used in practice whenever standard methods of transfer pricing are not applicable (Miller et al., 2009, para 14.17; OECD 2008).

\section{Regulated profit splitting}

Let $\sigma$ be the share of the licensee's profit paid to the licenser for sharing know-how. The term profit splitting is meant to imply that $\sigma$ is larger than zero and smaller than one. However, the degenerate cases equally play an important role in the analysis. The case characterized by $\sigma=0$ stands for a regime in which the return to know-how is taxed at source. This justifies speaking of source taxation. By contrast, we use the term residence taxation when $\sigma=1$. Finally, we speak of regulated profit splitting to stress the fact that $\sigma$ is treated by the MNE to be exogenous. The profit to be split in the model is the one of the sharing division, $f-r k$. This amounts to setting $R_{e}(I) \equiv \sigma[f(I, k)-r k]$.

The specific feature of regulated profit splitting is that there is no leeway for profit shifting. Other than in the next section, there is no transfer price which can be optimally chosen in reaction to internationally differentiated tax rates. In a regime of regulated profit splitting, the MNE's control is restricted to the choice of production inputs. Such choice is optimal if the profit after tax is maximized. A first noteworthy result is that is makes no real difference whether the MNE is decentralized or centralized. In both cases, the profit maximizing $I$ is characterized by

$$
(1-T)\left[F_{I}+f_{I}\right]=(1-\delta T) V^{\prime}-(T-t)(1-\sigma) f_{I}
$$

More precisely, eq. (3) is obtained when a centralized MNE maximizes the divisions' joint profit $\pi+\Pi$ in $I$. It equally results from decentralized decision making. By definition, decentralization means, that each division maximizes its own profit while taking the pricing of transferred know-how as given. By doing so, the divisions derive supplied and demanded know-how as functions of $R_{i}^{\prime}$. If the internal pricing is proportional, $R_{i}(I) \equiv P_{i} I$, a price $P_{i}=R_{i}^{\prime}$ exists equating supply and demand. In practice, one can think of a headquarter fixing the price. By eliminating the price from the market clearing condition eq. (3) is obtained. The point is that the internal pricing must be proportional if decentralized and centralized management is to have equivalent implications. In practice, the right to use a patent is often 
paid lump-sum. Hence, assuming proportional pricing to be feasible is not innocuous. However, the assumption is defensible if the modeled know-how is cardinally measurable.

Proposition 1: If internal pricing is proportional, regulated profit splitting does not distort the choice between centralized and decentralized management.

Let $\bar{I}_{\sigma}$ denote the optimal amount of know-how as a function of the splitting parameter $\sigma$. The optimal development of know-how is compared with the efficient amount. The quantity $I^{*}$ is called (production) efficient if the sum of marginal productivities equals the marginal cost, $F_{I}+f_{I}=V^{\prime}$. This is Samuelson's rule to be compared with eq. (3). Obviously, efficiency of optimal know-how is ensured if the costs of $\mathrm{R} \& \mathrm{D}$ are deductible, $\delta=1$, and if residence taxation applies, $\sigma=1$. Residence taxation has the effect to ensure that the developing division's internal and external returns to R\&D are taxed uniformly. Efficiency, however, results only if such uniform taxation extends to costs. The latter must be deductible at the same rate at which revenues are taxed. By contrast, if costs of $\mathrm{R} \& \mathrm{D}$ are not deductible, $\delta=0$, it may be efficiency enhancing not to rely on residence taxation.

To see this, assume $\delta=0$ and $T \neq t$. In this case, the development of know-how suffers from two tax distortions. One results from the non-deductibility of costs. If it were the sole distortion, the optimal know-how would fall short of the efficient level. As this distortion even exists in a closed economy, we call it the national tax distortion. The other distortion is indicated in eq. (3) by the last term on the right-hand side. It results from the international difference in tax rates which suggests calling it the international tax distortion. When $T>t$, the effect works like a subsidy to R\&D. The optimal development of know-how exceeds the efficient level when some part of benefits is taxed at a lower rate than the rate at which costs are deducted. The national distortion is, however, stronger in the sense that it is never fully compensated by the international distortion. See figure below. The national distortion is even strengthened by the international one if $T<t$. By contrast, some mitigation is achieved if 
$T>t$ holds. The mitigation is strongest when taxing at source and setting $\sigma=0 .{ }^{4}$ If, however, $T<t$, efficiency in know-how is best ensured by relying on residence taxation.

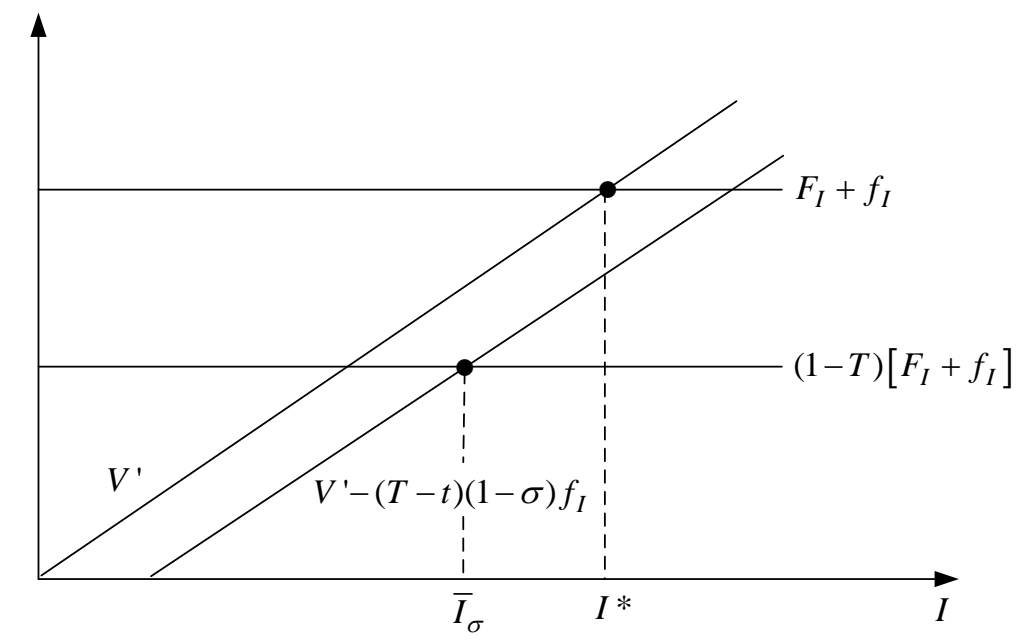

Figure: Optimal know-how when costs are not deductible and $T>t$

Proposition 2: If all costs are deductible,

(i) efficiency in the development of know-how is ensured by residence taxation;

(ii) the development of know-how will exceed the efficient level if a regime of source taxation or regulated profit splitting is implemented.

Proposition 3: If costs are not deductible, the resulting inefficiency in the development of know-how is minimized

(i) by residence taxation when $T<t$;

(ii) by source taxation when $T>t$.

It is suggestive to interpret regulated profit splitting as a compromise between residence and source taxation. In view of Proposition 3, it is equally suggestive to justify regulated profit

\footnotetext{
${ }^{4}$ Irrespective of which $\sigma \in[0,1]$ is chosen, optimal know-how will not reach the efficient level $I^{*}$. This is because $(1-T)\left[F_{I}+f_{I}\right]+(T-t)(1-\sigma) f_{I}<F_{I}+f_{I} \Leftrightarrow \frac{T-t}{T}(1-\sigma)<\frac{F_{I}}{f_{I}}+1$. The latter inequality holds true because the right-hand side exceeds one and the left-hand side is smaller than one.
} 
splitting by the attempt to find a policy compromise between high and low-tax countries for a problem of second-best allocation.

\section{Uniform pricing of IP}

When the pricing of transferred know-how is not perfectly prescribed by tax law, the leeway in setting those prices can be but need not be used by firms. The prices can be set actively or not. Let us speak of controlled pricing if MNEs take an active role in setting the transfer prices. By contrast, we speak of uncontrolled pricing if MNEs take a laissez-faire stance visà-vis the pricing of transferred know-how. In this case the price results from the pure need to equate the MNE's divisions' demand and supply of know-how. The MNE is decentralized and the divisions are assumed to behave as price-takers. Our interest in uncontrolled pricing is a purely theoretical one. In practice, MNEs can be expected to exploit any given leeway in the pricing of transferred know-how for minimizing their tax bill. Still, uncontrolled pricing serves as a kind of benchmark. Under some ideal circumstances which are spelled out next uncontrolled pricing is able to sustain efficiency in the development of know-how.

\subsection{Uncontrolled uniform pricing}

Consider the case that the management of the MNE is decentralized. Each MNE's division maximizes its own profit while taking the pricing of transferred know-how as given. The sharing division's profit after tax is

$$
\pi \equiv\left[f-r k-R_{i}(I)\right]-t\left[f-r k-R_{e}(I)\right]-w R_{e}(I)
$$

The added term $w R_{e}(I)$ allows for the case that royalty payments are liable to a withholding tax as proposed by Fuest at al. (2013). Assuming the withholding tax to be creditable, the developing division's profit after tax is

$$
\Pi \equiv\left[F+R_{i}(I)-r K\right]-T\left[F+R_{e}(I)-r K\right]+w R_{e}(I)+(1-\delta T) V(I) .
$$

Maximizing $\pi$ in $I$ yields

$$
f_{I}=\frac{R_{i}^{\prime}-(t-w) R_{e}^{\prime}}{1-t}
$$


and maximizing $\Pi$ in $I$ yields

$$
F_{I}+\frac{R_{i}^{\prime}-(T-w) R_{e}^{\prime}}{1-T}=\frac{1-\delta T}{1-T} V^{\prime}
$$

The term $\frac{R_{i}^{\prime}-(T-w) R_{e}^{\prime}}{1-T}$ can be interpreted as the developing division's effective price fetched for supplied know-how, $I^{s}$. Similarly, $\frac{R_{i}^{\prime}-(t-w) R_{e}^{\prime}}{1-t}$ is the sharing division's effective cost of demanded know-how, $I^{d}$. The development of know-how is efficient if the sum of marginal productivities equals the marginal cost, $F_{I}+f_{I}=V^{\prime}$. Obviously, efficiency requires tax deductibility of costs, $\delta=1$, and the equality of the effective price and cost of know-how, $\frac{R_{i}^{\prime}-(T-w) R_{e}^{\prime}}{1-T}=\frac{R_{i}^{\prime}-(t-w) R_{e}^{\prime}}{1-t}$, at $I^{S}=I^{d}$. At unequal tax rates such an equality is ensured only if the pricing is uniform and proportional, $R_{i}^{\prime}=P_{i}=P_{e}=R_{e}^{\prime}$, and if no withholding tax is levied, $w=0$.

Proposition 4: If the MNE's divisions maximize their respective profits at given transfer prices, efficiency in the development of know-how is achieved if (i) all costs are deductible, (ii) the pricing of transfers is uniform and proportional, and (iii) withholding taxes on royalty payments are not levied.

Proposition 4 replicates a key result of Desai and Dharmapala (2011). The replication clarifies the assumptions needed to sustain efficiency. Some of them are more difficult to ensure in practice than others. The least problem is raised by the exclusion of withholding taxes. As a matter of fact, the OECD model convention excludes withholding taxes on royalties. Royalties are taxed in the country in which the beneficiary is resident. Uniform proportional pricing is more difficult to ensure as it requires international policy coordination. Still, governments could consider agreeing on such pricing rule as, in fact, is recommended by Desai et al. (2011). Ensuring deductibility of costs is arguably more difficult to ensure in practice. Prescribing uncontrolled pricing is even totally unrealistic. Such a judgment suggests taking a closer look at the scenario in which transfer pricing is uniform but controlled and in which costs can be but need not be deductible. 


\subsection{Controlled uniform pricing}

Let the pricing of transferred know-how be uniform and proportional, $R_{i}(I)=R_{e}(I) \equiv P I$. The control of prices is by its very nature a centralized function. Hence, let us assume that the MNE's headquarter chooses $P$ out of an interval of feasible prices regulated by tax law, $P \in[\underline{P}, \bar{P}]$. By definition, one can only speak of a centralized MNE if the headquarter's pricesetting competence outreaches the task of balancing the divisions' demand and supply of know-how. In what follows, we focus on the scenario in which all decisions concerning the setting of quantities and the pricing of transferred know-how are centralized. Withholding taxes are ignored as they have no effect on the decisions of a centralized MNE.

Maximizing joint profit,

$$
\pi+\Pi=(1-t)[f-r k-P I]+(1-T)[F+P I-r K]-(1-\delta T) V(I),
$$

in $I$ yields

$$
(1-T)\left[F_{I}+f_{I}\right]=(1-\delta T) V^{\prime}-(T-t)\left[f_{I}-P\right]
$$

Let $\bar{I}_{P}$ denote the optimal amount of know-how in a regime of controlled uniform (and proportional) prices. The objective to minimize tax payments will induce the MNE's headquarter to set $P=\underline{P}$ if $T>t$ and $P=\bar{P}$ if $T<t$. This behavior raises the question of how to model the boundaries of feasible transfer prices.

An upper bound can be derived from the requirement that transfer prices do not imply losses. In the present framework with no uncertainty, a loss can only result when a claim for tax refund is planned. For this reason, tax authorities can be expected to reject reported royalty payments implying losses. Assuming $T<t$ and maximizing joint profit (6) subject to $\pi \geq 0$ yields $\bar{P}=\left[f-k f_{k}\right] / I$ and

$$
(1-T)\left[F_{I}+f_{I}\right]=(1-\delta T) V^{\prime}
$$

As a result, optimal know-how is efficient if costs are tax deductible. By contrast, optimal know-how falls below the efficient level if costs are not deductible.

If $T>t$, profit decreases in royalty payments. It then pays for the MNE to set $P$ as low as possible. This is without drawback as transfer prices have no managerial function in a fully centralized MNE. The only negative effect is on the tax revenue of the high-tax country. This 
will give its tax authorities reason to negotiate the choice of specific prices. In practice, their position is, however, weak because information about the marginal productivity of know-how is typically not available. The informational asymmetry gives the centralized MNE a lot of leeway in setting $P$. Just for the sake of simplicity, let us assume that the choice of $P$ is only constrained to be nonnegative. Negative transfer prices would certainly be challenged by tax authorities. The MNE's optimal choice then requires setting $P=\underline{P}=0$ and optimal knowhow $\bar{I}_{P}$ solves

$$
(1-T)\left[F_{I}+f_{I}\right]=(1-\delta T) V^{\prime}-(T-t) f_{I}
$$

if $T>t$. The last term on the right-hand side of eq. (9) works in the direction of reducing the cost of know-how. This is inefficient when costs are deductible. The development of knowhow exceeds the efficient level when some part of benefits is taxed at a lower rate than the rate at which costs are deducted. The cost reduction is, however, efficiency enhancing when the costs of know-how are not deductible. Still, $\bar{I}_{P}$ remains below the efficient level $I^{*}$ as the effect of cost reduction is not strong enough to fully compensate the non-deductibility of costs. See fn. 4 for $\sigma=0$. Let us summarize the main findings of this section.

Proposition 5: If costs are deductible, controlled uniform pricing is expected

(i) to sustain efficiency in the development of know-how when $T<t$ and

(ii) to encourage too much effort in the development of know-how when $T>t$.

Proposition 6: If costs are not deductible, controlled uniform pricing is expected to sustain too little know-how. If there is a positive tax gap, $T>t$, profit shifting has the effect of mitigating the inefficiency resulting from the non-deductibility of costs.

\section{Comparing uniform pricing with regulated profit splitting}

Let us compare uniform pricing with regulated profit splitting. As the allocational effect of uniform pricing differs between the centralized and the decentralized scenarios we have to 
decide which one to select for the comparison. We choose the centralized scenario. As shown, decentralization conflicts with the MNE's objective to maximize profit after tax. At least, this is so in the present model which ignores potential imperfections in the management of MNEs which are fought by way of decentralization. The need to choose between controlled and uncontrolled uniform pricing while regulated profit splitting raises no such need highlights a first noteworthy difference. Uniform pricing fails to be neutral with respect to the choice of management while regulated profit splitting is neutral.

Proposition 7: Regulated profit splitting is neutral with respect to the choice between decentralized or centralized management while uniform pricing is not.

Comparing eq. (3) with eq. (8) and (9) reveals the following equivalences. Controlled uniform pricing is equivalent to

$$
\text { source taxation, } \bar{I}_{P}=\bar{I}_{\sigma=0} \text {, when } T>t, \underline{P}=0 \text {, }
$$

while it is equivalent to

$$
\text { residence taxation, } \bar{I}_{P}=\bar{I}_{\sigma=1} \text {, when } T<t, \bar{P}=\left[f-k f_{k}\right] / I \text {. }
$$

Uniform pricing sets incentives for shifting profit to the low-tax country. The stated equivalences then follow from the assumption that royalty payments may be neither negative nor the cause of a deficit.

Proposition 8: Uniform pricing sets incentives for profit shifting which regulated profit splitting does not.

In the present model, profit shifting is not per se problematic. Quite to the contrary, it tends to enhance efficiency when the development of know-how suffers from a national distortion. See Proposition 3. If the costs are not deductible and if $T>t$, the inefficiency in the development of know-how is minimized by source taxation. The inefficiency is, however, not minimized 
by source taxation if $T<t$. Residence taxation sustains higher efficiency in this case. The great advantage of uniform pricing over residence or source taxation - and over regulated profit splitting a fortiori - is that it admits profit shifting in the case in which profit shifting is efficiency enhancing. Profit is shifted when $T>t$ and it is not shifted when $T<t$ and both reactions are efficiency enhancing.

Proposition 9: If costs are not deductible, uniform pricing dominates all specifications of regulated profit splitting including residence and source taxation in the secondbest sense that the inefficiency in the development of know-how is minimal irrespective of whether $T>t$ or $T<t$.

No comparable result is obtained in the first-best framework in which costs are deductible. In this case, the ranking depends on the sign of the international tax gap. If $T<t$, controlled uniform pricing sustains efficient outcomes while regulated profit splitting does not do so. By contrast, if $T>t$, the distortion in the development of know-how is larger under controlled uniform pricing. Compare eq. (3) and eq. (9) for $\delta=1, \sigma>0$. Hence an unambiguous ranking of regulated profit splitting and uniform pricing is not possible in terms of the resulting efficiency in know-how.

Summarizing the discussion one must say that the two transfer pricing rules we have been comparing do both have distinct advantages. Uniform pricing has the advantage of admitting profit shifting in such cases in which profit splitting has the effect of mitigating a national tax distortion. By contrast, regulated profit splitting constrains base erosion and profit shifting. Neither does it distort the choice between centralized and decentralized management. Furthermore, with the profit splitting parameter it offers policy flexibility to compromise between the requirements of first-best and second-best efficiency and also between the opposing interests of high- and low-tax countries.

\section{Summary and concluding remarks}

Pricing the transfer of intellectual property is one of the challenging tasks in the field of international transfer pricing. The task is challenging because an ideal method of pricing does 
not seem to exist. Standard methods of transfer pricing are not applicable because sufficiently comparable third-party data are typically not available. By contrast, profit-based methods seem to lack any sound normative justification.

Considerations of equity seem to be mistaken, for legal entities can hardly be the object of equity from an economic point of view. And even if one is prepared to apply notions of equity to legal entities, one encounters the difficulty of doing justice to two entities one of which develops and uses know-how while the other only uses the provided know-how. This fundamental asymmetry must be considered to be a - if not the - major reason why formula apportionment fails to be a truly convincing concept for taxing MNEs. After all, the wish to exploit know-how is considered to be the primary motive for undertaking foreign direct investment (Dunning, 1977).

Considerations of efficiency support the view that external benefits of know-how should be exclusively assigned to the developer of the know-how. Such exclusive assignment ensures an efficient internalization of the external benefits generated by R\&D. Against this background it is difficult to understand why profit-sharing methods play such a prominent role in the practice of pricing transferred IP.

A possible explanation is based on the recognition that external benefits can only be reaped in a foreign country if that country provides the necessary public infrastructure. Following this explanation, regulated profit splitting would constitute a compromise between the complementary roles and competing claims of the countries in which MNEs are active. The present paper offers and elaborates a different and purely tax-based explanation.

This explanation relies on the assumption that the overarching goal of transfer pricing policy is the enhancement of global efficiency in the development of know-how. The global planner accepts international differences in tax rates and internalizes the MNEs' inclination to exploit any leeway in setting transfer prices for trading off the efficiency in the development of know-how against the saving of taxes. In a framework in which an international tax gap were the sole source of inefficiency, one would still have difficulty in appreciating the merit of regulated profit splitting. After all, the policy of implementing residence taxation and assigning all external benefits to the developer of know-how would not only set incentives for internalizing the externality: the policy would also stop the MNE from engaging in profit shifting. 
Hence to understand the potential merit of regulated profit splitting in a purely tax-based framework one must think of scenarios in which tax evasion has an efficiency-enhancing effect. This is the case when the development of know-how would be inefficiently low even in a closed economy. Such a scenario gives rise to a problem for which a second-best solution is to be found. The model of the present paper is such that taxation is the source of two distorted margins. There is a national tax distortion in the development of know-how, which is mitigated by the international tax distortion. In such a situation, it is no longer efficient to implement residence taxation. ${ }^{5}$

Regulated profit splitting thus finds its justification as a policy coping with a second-best problem. Still, one may wonder why there do not exist more efficient policies. One policy which may come to one's mind is uniform pricing. And indeed, it has been shown in the present study that uniform pricing dominates all specifications of regulated profit splitting including residence and source taxation in the second-best sense that the inefficiency in the development of know-how is minimal. The big caveat of uniform pricing is that it sets incentives for centralizing management and saving taxes. Regulated profit splitting is neutral in theses respects. Hence, both transfer pricing rules are seen to have distinct merits. An ultimate ranking is therefore not free of the setting of priorities in competing policy dimensions.

One cannot finish such an analysis without stressing the theoretical nature of the obtained results. They rely on a whole array of simplifying assumptions which clearly limit the applicability. The following simplifying assumptions deserve to be stressed more than others. First, potential imperfections in the management of MNEs which are fought by way of decentralization have been ignored. In the model, centralization only promises benefits and no costs. Future research will have to explore the implications of removing this simplification. Second, the cost of capital has been assumed to be tax deductible even though the costs of know-how are not necessarily tax deductible. This somewhat unusual combination of assumptions is justified by the wish to focus on the efficiency effects of pricing know-how as against the efficiency effects of financing R\&D. Third, taxes only differ internationally with respect to rates. There is no double taxation of corporate and personal income at the national level. Forth, preferential tax provisions for $R \& D$ activities which are widely granted in practice are not modeled. Two particular policies stand out (Evers et al., forthcoming). One of these targets the cost side of $R \& D$ investment by granting $R \& D$ tax credits or super-

\footnotetext{
${ }^{5}$ If costs of know-how are not tax deductible, the production efficiency theorem of Diamond and Mirrlees (1971) does no longer apply.
} 
deductions. The other provides substantially reduced nominal and/or effective rates of corporate tax for income derived from important forms of IP. This is achieved by so called IP box regimes which are currently operated by eleven European countries.

The last simplifying assumption to be stressed relates to the ownership rights derived from generated know-how. This paper disregards the possibility of unbundling. The division developing know-how remains the owner of the asset. In practice, this is not necessarily the case. A wide spread example is the functional separation of development and risk bearing. In the standard scenario, one affiliated company carries out $R \& D$ while another affiliate bears the risk associated with the success or failure of the activities. Purely economic reasons may suggest such a functional specialization. There is, however, increasing evidence that MNEs use the unbundling of ownership rights to cut their tax bill (Evers et al., forthcoming; Schreiber, 2013, Sec. 3.2.4). That tendency has prompted more and more countries to take counteractions and to support the OECD (2013) BEPS-initiative directed against base erosion and profit shifting. For the time being, however, IP holding companies remain a frequently used tax-planning instrument of MNEs, a substantive discussion of which would lead us beyond the scope of this paper.

\section{References}

Benson, Edgar J. (1971): Statement by Finance Minister E. J. Benson to the FederalProvincial Conference of Prime Ministers and Premiers, February 9, 1971.

Boos, Monica (2003): International Transfer Pricing: The Valuation of Intangible Assets, The Hague.

Dharmapala, Dhammika (2014): What Do We Know about Base Erosion and Profit Splitting? A review of the Empirical Literature, Fiscal Studies 35, 421-448.

Desai, Mihir A.; Dharmapala, Dhammika (2011): An Alternative Transfer Pricing Norm, Working Paper, Harvard Business School and University of Illinois at Urbana-Champaign.

Diamond, Peter; Mirrlees, James A. (1971): Optimal Taxation and Public Production, I Production Efficiency, II Tax Rules, American Economic Review 61, 8-27, 261-278. 
Dischinger, Matthias; Riedel, Nadine (2011): Corporate Taxes, Profit Shifting and the Location of Intangibles within Multinational Firms, Journal of Public Economics 95, 691707.

Dunning, John H. (1977): Trade, Location of Economic Activity and the MNE: A Search for an Eclectic Approach, in: The International Allocation of Economic Activity, Ohlin, Bertil; Hesselborn, Per-Ove; Wijkman, Per Magnus, eds., London: Macmillan, 395-418.

Edlin, Aaron S.; Reichelstein, Stefan (1995): Specific Investment Under Negotiated Transfer Pricing: An Efficiency Result, The Accounting Review 70, 275-291.

Evers, Lisa; Miller, Helen; Spengel, Christoph (forthcoming): Intellectual Property Box Regimes: Effective Tax Rates and Tax Policy Considerations, International Tax and Public Finance, DOI 10.1007/s10797-014-9328-x.

Fuest, Clemens; Spengel, Christoph; Finke, Katharina; Heckemeyer, Jost; Nusser, Hannah (2013): Profit Shifting ans 'Aggressive’ Tax Planning by Multinational Firms: Issues and Options for Reform, ZEW Discussion Paper No. 13-044.

Goldscheider, Robert; Jarosz, John; Mulhern, Carla (2005): Use of the 25\% rule in valuing intellectual property, in: Intellectual Property: Valuation, Exploitation, and Infringement Damages, Smith, Gordon V.; Parr, Russell L., eds., John Wiley and Sons, 410-426.

Griffith, Rachel; Miller, Helen (2014): Taxable Corporate Profits, Fiscal Studies 35, 535-557.

Griffith, Rachel; Miller, Helen; O‘Connell, Martin (2011): Corporate Taxes and the Location of Intellectual Property, CEPR Discussion Paper 8424.

Grubert, Harry (2003): Intangible Income Intercompany Transactions, Income Shifting, and the Choice of Location, National Tax Journal 56, 221-242.

Heckemeyer, Jost H.; Overesch, Michael (2013): Multinationals' Profit Response to Tax Differentials: Effect Size and Shifting Channels, ZEW Discussion Paper 13-045.

Hiemann, Moritz; Reichelstein, Stefan (2012): Transfer Pricing in Multinational Corporations: An Integrated Management- and Tax Perspective, in: Fundamentals in International Transfer Pricing in Law and Economics, Schön, Wolfgang; Konrad, Kai A., eds., MPIS Studies in Tax Law and Public Finance 1, Berlin and Heidelberg, 3-18. 
Hirshleifer; Jack (1956): On the Economics of Transfer Pricing, The Journal of Business 29, $172-184$.

Horst, Thomas (1973): The Simple Analytics of Multinational Firm Behavior, in: International Trade and Money, Connolly, M. B.; Swoboda, A. K. eds., London: Allen and Unwin, 72-80.

Johnson, Nicole Bastian (2006): Divisional Performance Measurement and Transfer Pricing for Intangible Assets, Review of Accounting Studies 11, 339-365.

Karkinsky, Tom; Riedel, Nadine (2012): Corporate Taxation and the Choice of Patent Location within Multinational Firms, Journal of International Economics 88, 176-185.

Knoppe, Helmut (1972): Die Besteuerung der Lizenz- und Know-how-Verträge, Berlin.

Miller, Angharard; Oats, Lynne (2009): Principles of International Taxation, Tottel Publishing, Haywards Heath, Sussex.

OECD (2008): Transactional Profit Methods: Discussion Draft for Public Comment, Paris.

OECD (2010): OECD Transfer Pricing Guidelines for Multinational Enterprises and Tax Authorities, Paris.

OECD (2013): Action Plan on Base Erosion and Profit Shifting, Paris.

Mutti, John; Grubert, Harry (2009): The Effect of Taxes on Royalties and the Migration of Intangible Assets Abroad, in: International Trade in Services and Intangibles in the Era of Globalization, Reinsdorf, Marshall; Slaughter, Matthew J., eds., University of Chicago Press, 111-137.

Nielsen, Soren Bo (2014): Transfer Pricing: Roles and Regimes, Journal of World Economy/Revista de Economia Mundial 37, 103-122.

Parr, Russell L. (2013): Intellectual Property: Valuation, Exploitation and Infringement Damages, Cumulative Supplement, 11th Edition.

Schön, Wolfgang; Konrad, Kai A. (2012): Fundamentals in International Transfer Pricing in Law and Economics, Heidelberg, Springer.

Schreiber, Ulrich (2013): International Company Taxation, Heidelberg, Springer. 
Wellisch, Dietmar (2003) Internationale Verrechnungspreismethoden, Neutralität und die Gewinne multinationaler Unternehmen, Journal of Economics and Statistics (Jahrbuecher fuer Nationaloekonomie und Statistik) 223, 332-359 and 464-478. 